Article

\title{
Rainwater Harvesting for Small-Holder Horticulture in Namibia: Design of Garden Variants and Assessment of Climate Change Impacts and Adaptation
}

\author{
Laura Woltersdorf ${ }^{1, *}$, Stefan Liehr ${ }^{1}$ and Petra Döll ${ }^{2}$ \\ 1 Institute for Social-Ecological Research (ISOE), Hamburger Allee 45, Frankfurt am Main 60486, \\ Germany; E-Mail: liehr@isoe.de \\ 2 Institute of Physical Geography, Goethe University, Altenhöferallee 1, Frankfurt am Main 60438, \\ Germany; E-Mail: p.doell@em.uni-frankfurt.de \\ * Author to whom correspondence should be addressed; E-Mail: woltersdorf@isoe.de; \\ Tel.: +49-69-707-691-941; Fax: +49-69-707-691-911.
}

Academic Editor: Ataur Rahman

Received: 20 December 2014 / Accepted: 5 March 2015 / Published: 30 March 2015

\begin{abstract}
The design of rainwater harvesting based gardens requires considering current climate but also climate change during the lifespan of the facility. The goal of this study is to present an approach for designing garden variants that can be safely supplied with harvested rainwater, taking into account climate change and adaptation measures. In addition, the study presents a methodology to quantify the effects of climate change on rainwater harvesting based gardening. Results of the study may not be accurate due to the assumptions made for climate projections and may need to be further refined. We used a tank flow model and an irrigation water model. Then we established three simple climate scenarios and analyzed the impact of climate change on harvested rain and horticulture production for a semi-arid region in northern Namibia. In the two climate scenarios with decreased precipitation and medium/high temperature increase; adaptation measures are required to avoid substantial decreases in horticulture production. The study found that the most promising adaptation measures to sustain yields and revenues are a more water efficient garden variant and an enlargement of the roof size. The proposed measures can partly or completely compensate the negative impacts of climate change.
\end{abstract}


Keywords: rainwater harvesting; gardening; climate change; adaptation; scenario; semi-arid; Namibia

\section{Introduction}

The Intergovernmental Panel on Climate Change (IPCC) identified Africa as one of continents that are most vulnerable to climate variability and change because of the range of projected impacts, multiple stresses and low adaptive capacity [1]. Climate change will affect all facets of society and the environment, with strong implications for water and agriculture, in particular subsistence agriculture. Today, agriculture in Africa is mainly rain fed and highly vulnerable to strongly variable rainfall, in particular in semi-arid areas [1,2]. Rainwater harvesting is particularly indicated to raise the reliability of water supply for the irrigation of small gardens where traditional irrigation from surface or ground water is not feasible. This is expected to become even more important in the future in the light of population growth and increasing precipitation variability [3].

Rainwater harvesting consists of a wide range of technologies to collect, store and provide water for humans [4]. Rainwater can be harvested in rural and urban areas, from natural or artificial surfaces, such as roofs, roads, pavements, ground catchments or slopes. The rain is stored in wells, dams, ponds or cisterns [5,6]. Rooftop rainwater harvesting as well as gardening in general are new practices in the study region, north-central Namibia. Collected rainwater from well-constructed and maintained roof catchments usually represents a significant improvement compared to these unprotected, traditional water sources and is generally safe to drink without further treatment [7]. This study focuses on domestic rainwater harvesting with household rooftops as collection surface and tanks as storage medium. The collected water is intended to be used exclusively for the irrigation of small garden plots (Figure 1) in order to improve food security, the daily diet and the household income of rural inhabitants in the region.

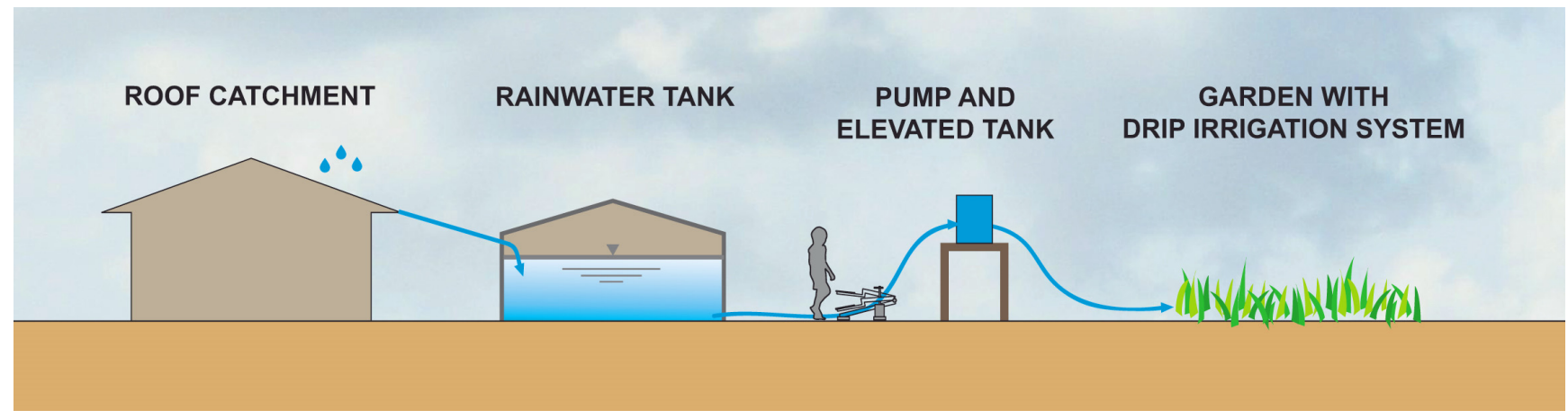

Figure 1. Rainwater harvesting and gardening facility with roof catchment and storage tank [8].

The planning of rainwater harvesting based gardening is dependent on several climatic factors. Especially high inter-annual and inter-seasonal precipitation variability in semi-arid areas represents a challenge [9]. In addition, crop yields and irrigation requirements are also affected by evaporative demand, which is a function of net radiation, air humidity, wind and temperature. With climate change, temperatures and thus evaporative demand are expected to increase. Precipitation volumes may either 
increase or decrease depending on the projection model and the region considered [10]. Several studies have examined aspects of rooftop rainwater harvesting in Sub-Saharan Africa in general [11,12] some as an adaptation measure to climate change, focusing e.g., on health impacts [13] or the optimum size of the tanks on the catchment scale [14]. Lupia and Pulighe [15] investigated the water use of residential kitchen gardens in Rome, Italy, and the irrigation with harvested rainwater. Other studies, such as Hajani and Rahman [16] performed water-balance simulation models to calculate the optimal rainwater harvesting tank size. However, so far no studies have shown the impacts of future climate change on rooftop rainwater harvesting used for small-holder gardening coupled with climate change impacts on irrigation requirements at the local scale. Considering a lifespan of rainwater harvesting facilities of 40 years (see [17]), future impacts of climate change have to be included into their design.

The goal of this study is to present an approach for designing small-scale horticulture garden variants that can safely be supplied with harvested rainwater, taking into account climate change. The study determines four garden variants that can be irrigated with harvested rainwater under current climate conditions and then analyses the impact of future climate change on horticulture production around the end of the 40-year lifespan of the tank. In addition, it identifies and evaluates possible climate change adaptation measures. As an example, we chose a location in semi-arid central-northern Namibia, where it is even uncertain whether precipitation will decrease or increase.

\section{Study Area}

Namibia is one of the driest sub-Saharan African countries. The study area, central-northern Namibia, has a semi-arid climate with highly variable rainfall in temporal and spatial terms (Figure 2). The town of Ondangwa has a mean annual rainfall of $464 \mathrm{~mm}$ occurring from November to April, the months with the highest temperatures and potential evaporation [18]. Annual potential evapotranspiration is $2600 \mathrm{~mm}$ [19]. The region is characterized by brackish or saline groundwater and ephemeral rivers [18]. Presently, most of the drinking water is extracted from the Calueque Dam on the Kunene River in Angola and is transported through canals and pipelines to the consumers in Namibia [19]. Important sources of water during and after the rainy season are the Oshanas, temporary wetlands, and hand-dug wells and dams that impound rain and runoff [7,19,20]. Alternating droughts and floods put severe stress and threaten the population's livelihoods [18]. The region faces considerable socio-economic dynamics related to food insecurity and high food imports, ongoing population growth and further urbanization. In the future, irrigated production of high value crops and irrigated subsistence farming are predicted to increase [21]. Climate change together with an increase in water demand is expected to adversely affect livelihoods, economies and environments and exacerbate prevailing water-related development constraints, including the achievement of the Millennium Development Goals [22]. For these reasons, rooftop rainwater harvesting based gardening has been introduced in the village of Epyeshona [7,23-25]. The village of Epyeshona (Okatana constituency, Oshana region) was jointly selected as the pilot site by the community and the Department of Rural Water Supply (DRWS) of the Oshana region. In a demand-responsive approach, including workshops and discussions with the inhabitants of Epyeshona and the future users of the pilot plants, the social realities of local community members were considered and all decisions were taken jointly by the project team as well as the stakeholders in a participatory manner (stakeholder 
participation). After the workshop, the community agreed on the type of rainwater harvesting facilities to build, determined their storage volume to be of $30 \mathrm{~m}^{3}$ and selected three households for their installation. The criteria that served as a guideline for choosing the beneficiaries were jointly selected and comprised, among others, the availability of corrugated iron roofs of sufficient size and the willingness of the future users to contribute to the construction of the facilities [24]. This study will examine the case of a household with a rainwater-harvesting tank with a $30-\mathrm{m}^{3}$ storage capacity and a $100-\mathrm{m}^{2}$ corrugated iron roof as catchment surface. The gardens were equipped with drip irrigation and surrounded by a fence. The study will examine the garden area that can be irrigated with the harvested rainwater of a $30-\mathrm{m}^{3}$ tank and from a $100-\mathrm{m}^{2}$ iron corrugated roof. For this, the study determined that the garden area should have a precise size so that the harvested water is sufficient for full irrigation in three out of four years ( $75 \%$ of years). Determining a garden area to be fully irrigated in a lower amount of years (e.g., 50\% of years) would allow for a larger garden, however it would also mean that in more years the garden cannot be fully irrigated. Full irrigation in a higher number of years (e.g., 100\% of years) would mean that the garden area is so small that in rainwater harvesting is left unused more often.

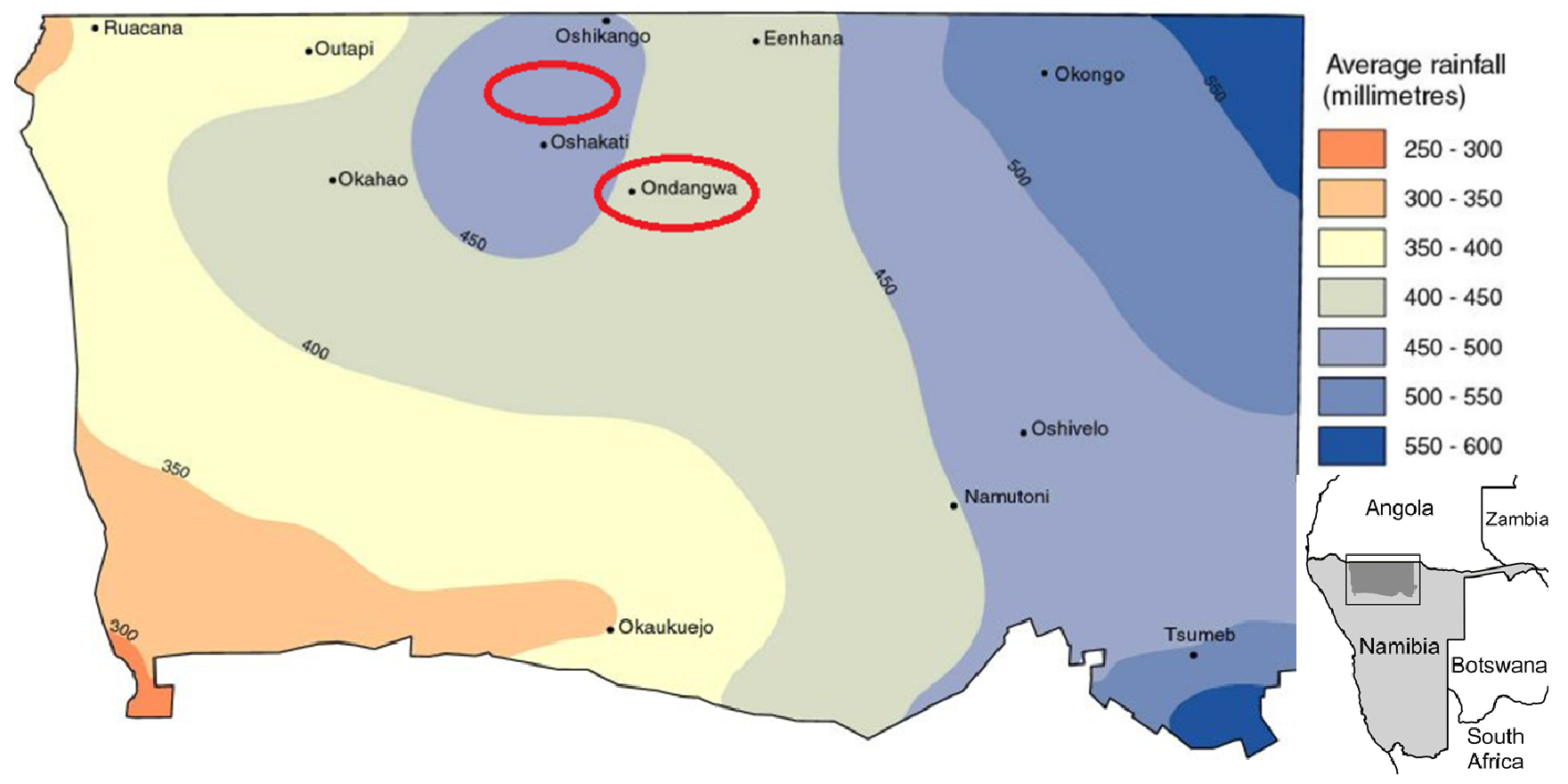

Figure 2. Map of central-northern Namibia with annual average rainfall [26] with marked project location and Ondangwa meteorological station and small map of Namibia [27].

\section{Methods and Data}

\subsection{Overview of Methodology}

The methodology of this study involves the analysis of the impacts of current and future climate change on rainwater harvesting and gardening (Figure 3). We used a simple tank flow model that combines precipitation on the catchment (tank inflow) and garden irrigation requirements (tank outflow) with the storage capacity of the tank. We created four garden variants based on different strategic objectives. With the model, we then determined different garden sizes and cropping patterns that can be reliably irrigated with harvested rainwater under current climate conditions. Three climate 
scenarios were developed for 2050 and used to analyze the impact of climate change on horticulture production in the four garden variants. With the model, we then determined the necessary adaptation of the garden size to the future climate scenario and optimized the garden area, so that tank failure occurs with the same frequency as in the current climate scenario. The study identified possible adaptation measures and evaluated them.

tank flow model

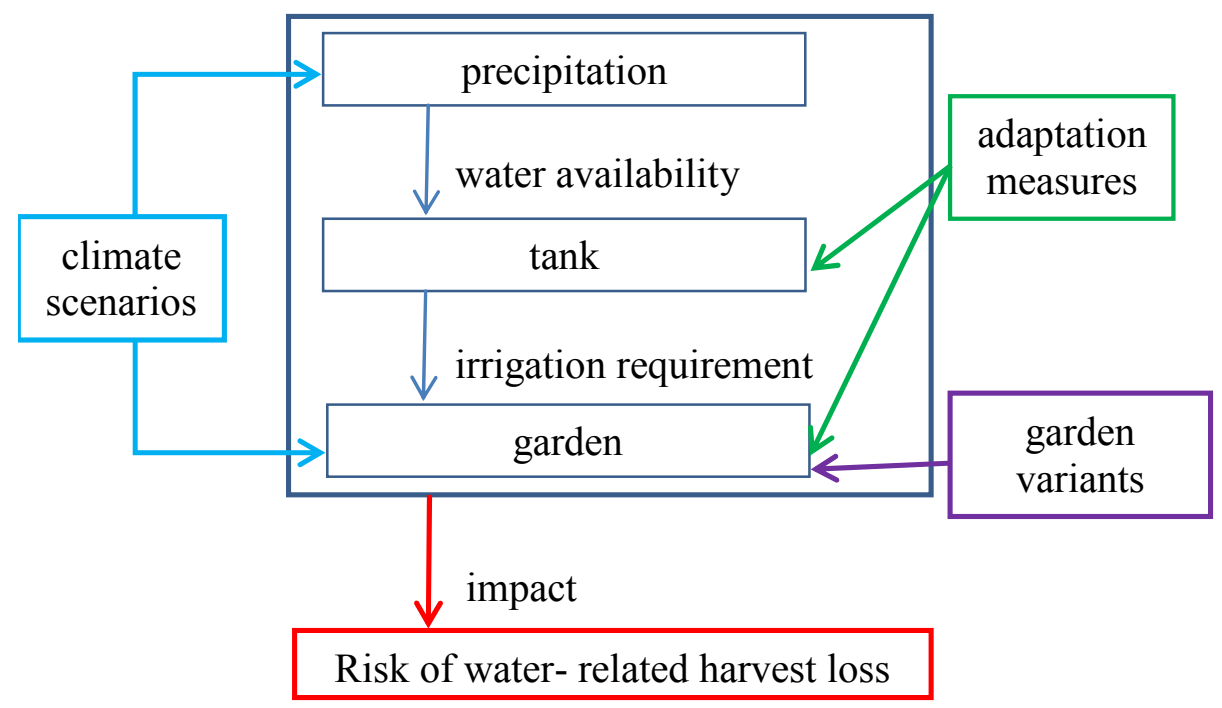

Figure 3. Overview of methodology.

\subsection{Modeling the Tank Balance}

The rainwater harvesting tank balance is computed with monthly time steps as:

$$
V(t i)=\min \left(V(t i-1)+Q(t i)-I R(t i) ; V_{\max }\right) \text {, with } V_{\max }=30 \mathrm{~m}^{3}
$$

where $V(t i)=$ volume of water stored in tank at the end of month $t i, V(t i-1)=$ volume stored in tank at the end of month $t i-1, Q(t i)=$ inflow of tank, dependent on precipitation on the catchment in month $t i$, and $I R(t i)=$ outflow, equal to gross irrigation requirement of garden in month $t i$. The tank balance is modeled with a monthly 30-year precipitation time series. The model integrated a maximum storage capacity of $30 \mathrm{~m}^{3}$. As the tank is a covered and closed ferrocement tank, when it is full, rainwater is diverted and no further water can enter the tank nor can water can spill out the tank.

\subsubsection{Modeling Tank Inflow}

A statistical precipitation probability analysis was carried out. Monthly tank inflow $Q(\mathrm{ti})$ was calculated as:

$$
Q(t i)=P(t i) \times C \times R
$$

where $P(t i)=$ precipitation in month $t i, C=$ catchment area, $R=$ roof runoff coefficient. A runoff coefficient for corrugated iron roof catchments of 0.85 as indicated by Gould and Nissen-Petersen (2006) and a mean household roof size in the pilot village $\left(C=100 \mathrm{~m}^{2}\right)$ was selected as indicated by Sturm et al., (2009). 


\subsubsection{Modeling Tank Outflow}

Net irrigation requirements on a monthly basis were computed using the software CROPWAT 8.0 developed by the Land and Water Development Division of the Food and Agricultural Organization. CROPWAT 8.0 is a practical computer program for the calculation of crop water requirements and irrigation requirements based on soil, climate and crop data. In addition, the program allows the calculation of scheme water supply for varying crop patterns. Input parameters included latitude, altitude, monthly precipitation, and length of daily sunshine, monthly mean minimum and maximum temperature, relative humidity, wind speed, and type of soil. The length of daily sunshine and the data for light sandy soil were taken as suggested by CROPWAT. We calculated monthly irrigation requirements for the past 30 years using available monthly precipitation data and mean monthly data for temperature, relative humidity and wind speed (see Section 3.3). We used crop-specific data for a semi-arid climate from Savva and Frenken [28] and as suggested by CROPWAT 8.0. Used output data of CROPWAT 8.0 included: crop evapotranspiration $\left(\mathrm{ET}_{\mathrm{c}}\right)(\mathrm{mm} /$ day) and net irrigation requirement $(\mathrm{mm} /$ day) indicated for each decade.

Finally, we multiplied the calculated net irrigation requirement with a drip irrigation efficiency of 0.75 (calculated according to Brouwer [29] as multiplication of the conveyance efficiency of 0.85 times the application efficiency of 0.9 ) to obtain gross irrigation requirements, i.e., the tank outflow [29].

\subsection{Climate Data and Scenarios}

Climate data from Ondangwa station was provided by the Namibian Weather Bureau [30]. Available data included monthly precipitation from 1903 to 2008 (incomplete); mean, minimum and maximum monthly temperature from 2003 to 2007; monthly mean relative humidity from 2004 to 2007; and monthly wind speed from 2006 to 2007. Before and after Namibian independence in 1990, precipitation was not recorded regularly and nearly half of the data is missing. For this reason, to obtain a 30-year data set of monthly precipitation, non-consecutive 30 years with reliable data, i.e., with data for the typical wet season, were combined, with 1950 being the earliest year and 2008 the most recent one. To compute monthly temperatures, relative humidity and wind speed, the time series available for each variable (see above) was used besides using the 30-year precipitation time series for the tank model. We used the $75 \%$ dependable rainfall when making general statements about the amount of average precipitation in this study. The reason for this is that the $75 \%$ dependable rainfall assures a higher reliability as compared to a design based on mean rainfall (see Section 4.1).

Precipitation and temperature projections of global climate models of the Forth Assessment Report of the Intergovernmental Panel on Climate Change [1] served to estimate the situation for rainwater harvesting and gardening until the end of the facility's lifespan in 2050. The report presents spatially averaged information on future changes of precipitation $(\%)$ and temperature $\left({ }^{\circ} \mathrm{C}\right)$ until 2080-2099 (compared to 1980-1999) for the South African subcontinent $\left(35^{\circ} \mathrm{S}, 10^{\circ} \mathrm{E}, 12^{\circ} \mathrm{S}, 52^{\circ} \mathrm{E}\right)$, from a set of 21 global climate model runs ( [10], Table 11.1). We assumed that relative humidity, wind speed and length of daily sunshine required to compute irrigation water requirements remain constant in the future. To estimate precipitation and temperature until 2050, we used temperature 
projections for the periods 2031-2050 and 2091-2100 that are available for the South African continent from the Japanese High Resolution general circulation model [31]. We observed that their projections for the period 2031 to 2050 are lower by $1 / 3$ compared to the period 2091 to 2100 . Therefore, to characterize climatic changes until 2050, we reduced the projected changes for temperature and precipitation until $2080-2099$ by $1 / 3$. Then we took the value of the regional projection for precipitation $(\%)$ and temperature $\left({ }^{\circ} \mathrm{C}\right)$ and added them to the present precipitation or temperature values. This is an estimation of future precipitation and temperature change, which is an estimate fit for our study and not an accurate climate projection. We generated three climate scenarios (Table 1): A best-case, a medium-case and a worst-case climate scenario, for which we combined the minimum, median and maximum temperature and precipitation response projections provided in Christensen [10] in Table 11.1.

Table 1. Created future climate scenarios for 2050.

\begin{tabular}{ccc}
\hline Scenarios & Temperature $\left({ }^{\circ} \mathbf{C}\right)$ & Precipitation (\%) \\
\hline Best future climate & minimum increase & maximum decrease \\
Medium future climate & median increase & median decrease \\
Worst future climate & maximum increase & minimum decrease \\
\hline
\end{tabular}

All climate model projections are for emissions scenario A1B [32]. For 2050, differences of climate model output for different emissions scenarios are small compared to range of projected climatic changes, in particular precipitation changes. This is why we can assume that our three climate scenarios that we derived for the study area also cover (almost) the full uncertainty due to different greenhouse gas emissions pathways. Mean temperature changes were added to daily minimum and maximum temperature. Future precipitation was computed by adding or subtracting the monthly projected change in the 30-year monthly time series. We determined the impact of climate change as the change of the fraction of years in which irrigation requirements can be fully satisfied with harvested rain. In order to determine whether precipitation had already decreased from 1903 to 2008, we carried out a linear regression $t$-test with the statistics software "R 11.0".

\section{Results and Discussion}

\subsection{Climate Analysis}

The statistical analysis of precipitation at Ondangwa station (data base: [30], Ondangwa station) resulted that the mean annual precipitation from 1950 to $2008(n=30)$ was $464 \mathrm{~mm}$ and occurred only with a probability level of $39 \%$. The rainfall that falls with a higher than $75 \%$ probability level, the $75 \%$ dependable rainfall, is $334 \mathrm{~mm}$. Bulk precipitation $(80 \%)$ occurs from December through March with highly variable quantities. In contrast, evaluating available precipitation data from 1903 to $2008(n=85)$, mean precipitation was $473 \mathrm{~mm}$. The linear regression t-test results show that mean annual precipitation from 1903 to 2008 has significantly decreased $(p=0.00502)$. Temperatures are the highest from October through March $\left(20\right.$ to $\left.35^{\circ} \mathrm{C}\right)$ and the lowest from May to August $\left(11\right.$ to $\left.31{ }^{\circ} \mathrm{C}\right)$. Mean annual reference crop evapotranspiration was computed with CROPWAT to be $1891 \mathrm{~mm}$, being 
the highest during the hottest months from September to March (151 to $230 \mathrm{~mm} / \mathrm{month}$ ) and lowest during the winter months from May to August ( 89 to $150 \mathrm{~mm} / \mathrm{month}$ ).

\subsection{Scenarios of Future Precipitation, Temperature and Reference Crop Evapotranspiration}

All 21 models considered by the IPCC, averaged over the Southern African sub- region, project temperature increases for all emission scenarios [10,32]. Under the A1B scenario (balanced development of energy technology) in the IPCC Special Report on Emissions Scenarios (SRES), mean annual temperatures are projected to increase by 1.9 to $4.8^{\circ} \mathrm{C}$ by 2080 to 2099 with the largest increases in the spring from September to November. We derived that until 2050, this corresponds to temperature increases between $+1.3{ }^{\circ} \mathrm{C}$ in the best case to $+3.2{ }^{\circ} \mathrm{C}$ in the worst case (Table 2). We project the $75 \%$ dependable precipitation to change from presently $334 \mathrm{~mm}$ by $+4 \%$ in the best (to $347 \mathrm{~mm}$ ), $-3 \%$ (to $325 \mathrm{~mm}$ ) in the medium and $-8 \%$ (to $307 \mathrm{~mm}$ ) in the worst case scenario (Table 2 and Figure 3 ).

Table 2. Scenarios with future temperature $\left({ }^{\circ} \mathrm{C}\right)$ and precipitation $(\%)$ change by 2050 compared to 1958 to 2008 computed for Ondangwa for A1B SRES emission scenario (data base: $[10,30,31]$.

\begin{tabular}{|c|c|c|c|c|c|c|}
\hline \multirow[b]{2}{*}{ Scenarios } & \multicolumn{3}{|c|}{ Temperature Change $\left({ }^{\circ} \mathrm{C}\right)$ for 2050} & \multicolumn{3}{|c|}{ Precipitation Change (\%) for 2050} \\
\hline & $\begin{array}{l}\text { Minimum } \\
\text { (Best Case) }\end{array}$ & $\begin{array}{c}\text { Median } \\
\text { (Medium Case) }\end{array}$ & $\begin{array}{c}\text { Maximum } \\
\text { (Worst Case) }\end{array}$ & $\begin{array}{c}\text { Minimum } \\
\text { (Worst Case) }\end{array}$ & $\begin{array}{c}\text { Median } \\
\text { (Medium Case) }\end{array}$ & $\begin{array}{l}\text { Maximum } \\
\text { (Best Case) }\end{array}$ \\
\hline December, January, February & +1.2 & +2.1 & +3.1 & -4 & 0 & +7 \\
\hline March, April, May & +1.1 & +2.1 & +3.1 & -17 & 0 & +8 \\
\hline June, July, August & +1.3 & +2.3 & +3.2 & -29 & -15.3 & -2 \\
\hline September, October, November & +1.4 & +2.5 & +3.3 & -29 & -8.7 & +2 \\
\hline Annual & +1.3 & +2.2 & +3.2 & -8 & $-\mathbf{3}$ & +4 \\
\hline
\end{tabular}

With these temperature increases, we project annual reference crop evapotranspiration to increase from currently $1891 \mathrm{~mm}$ by $+3 \%(1940 \mathrm{~mm})$ in the best, $+5 \%(1977 \mathrm{~mm})$ in the medium and to $+7 \%$ (2016 mm) in the worst-case climate scenario (Figure 4).

As irrigation requirements are closely related to the difference between reference crop evapotranspiration and precipitation, Figure 4 indicates that the change in reference crop evapotranspiration has a higher impact on irrigation requirements than the change in precipitation. For all scenarios, the strongest temperature increases and the strongest decreases of $75 \%$ dependable precipitation are projected for the autumn months September to November. Highest absolute increases of reference crop evapotranspiration are derived for October through December when reference crop evapotranspiration is highest under current climate conditions. 


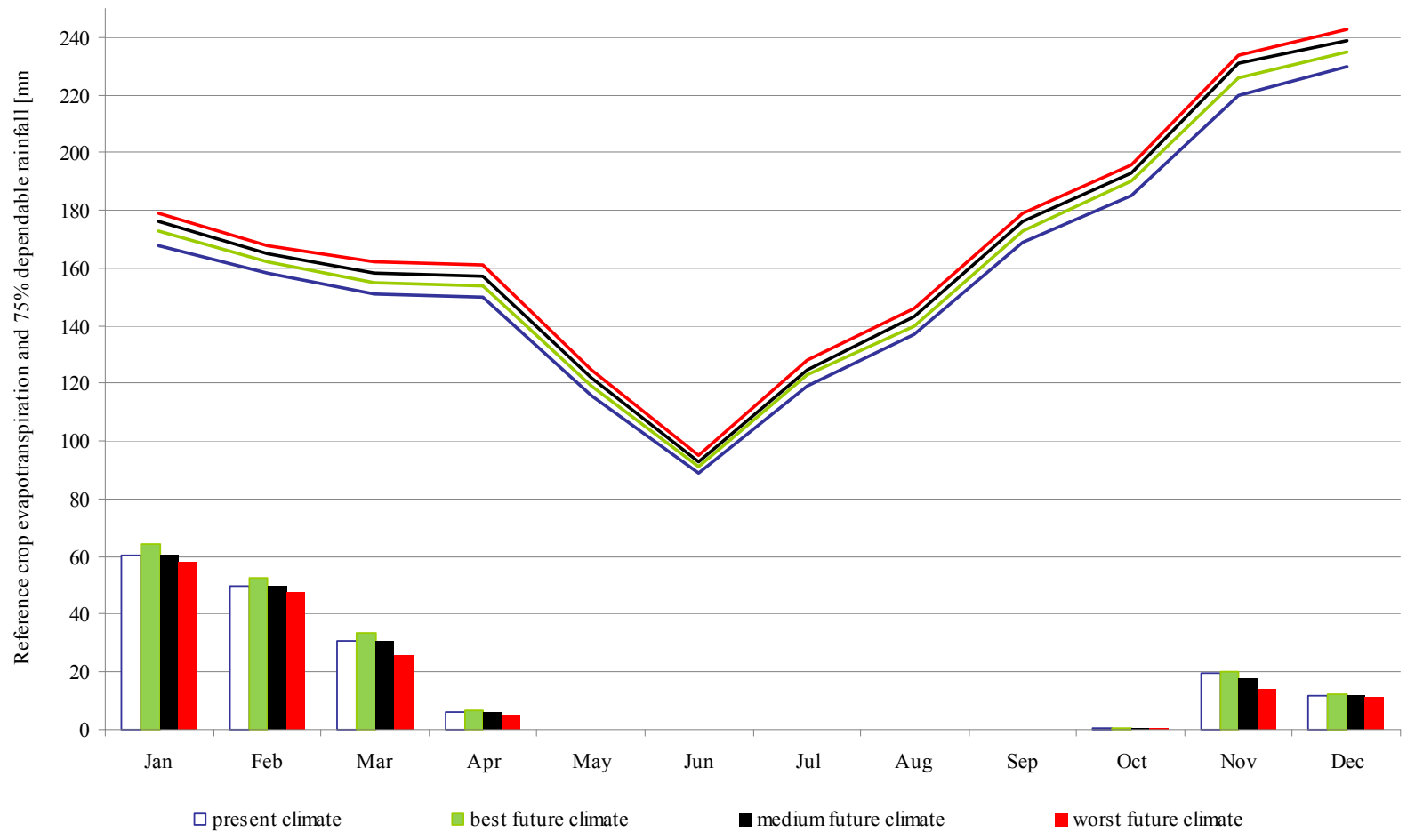

Figure 4. Projected $75 \%$ dependable rainfall $(\mathrm{mm})$ (bars) and projected reference crop evapotranspiration (mm) (line) for Ondangwa in 2050 under different climate scenarios (computed with Cropwat 8.0, data base: [10,34]).

\subsection{Garden Variants}

The four garden variants are a result of four contrasting strategic goals and can be irrigated with the harvested rainwater under current climate conditions. The variants differ in crop choice, water requirement, garden size, crop production and market revenue (Table 2). The choice of crops is based on local crop water requirements calculated with CROPWAT 8.0, yield in Namibia based on Price Waterhouse Coopers [33] and local crop preference based on Nantanga [34]. Planting dates were optimized considering irrigation requirements, precipitation, temperature and the time needed for sowing, transplanting, and harvesting and land preparation for the next crop [28]. The planting period with the lowest irrigation requirement over the crop's growth period is January and February, due to an optimal combination of high precipitation and relatively low reference crop evapotranspiration. Reference crop evapotranspiration is the highest in November and December due to high temperatures, low humidity and low cloudiness.

All garden variants (Table 3) are designed with one growing period per year, as we found that gardens achieve higher water efficiencies with one growing period starting in the rainy season than with two growing periods, with the second one during the dry season. The garden size was optimized according to water requirements so that the harvested rain is sufficient for irrigation in three out of four years, considering each month of the growing period. This probability level is considered adequate for irrigations schemes [9]. Within a garden variant, each crop is planted on the same share of garden area while each tree has a soil surface area of $1 \mathrm{~m}^{2}$. Crop production and revenues are given for three out of four years. Production and revenue reduction in the remaining one out of four years are not considered in this study. 
Table 3. Garden variants.

\begin{tabular}{|c|c|c|c|c|}
\hline Garden variants & Subsistence & Cash & Low Water & Super Cash \\
\hline Description & $\begin{array}{c}\text { Aimed for household } \\
\text { consumption, with high } \\
\text { nutritional value of crops } \\
\text { combining a healthy diet with } \\
\text { saved expenses for food. }\end{array}$ & $\begin{array}{l}\text { Maximizes revenue from } \\
\text { market sale, crops } \\
\text { combine high yields and } \\
\text { market with low water } \\
\text { requirements. }\end{array}$ & $\begin{array}{l}\text { Most water efficient } \\
\text { crops, market prices } \\
\text { are not considered. }\end{array}$ & $\begin{array}{l}\text { Maximizes revenues, by } \\
\text { planting the crop that } \\
\text { achieves the highest } \\
\text { market price through a } \\
\text { high yield and low water } \\
\text { requirement. }\end{array}$ \\
\hline Crops & $\begin{array}{l}\text { water melon, cucumber, } \\
\text { cabbage, pepper, tomato, } \\
\text { potato, } 1 \text { orange tree }\end{array}$ & $\begin{array}{c}\text { cucumber, lettuce, water } \\
\text { melon, } 1 \text { mango tree }\end{array}$ & $\begin{array}{l}\text { cucumber, water } \\
\text { melon, lettuce, } \\
\text { onions, zucchini, } \\
1 \text { avocado tree }\end{array}$ & cucumber \\
\hline Growing period & $\begin{array}{l}\text { 01 January-14 June } \\
\text { fruit tree all year }\end{array}$ & $\begin{array}{l}\text { 01 January-15 April } \\
\text { fruit tree all year }\end{array}$ & $\begin{array}{c}\text { 01 January-15 April } \\
\text { fruit tree all year }\end{array}$ & $\begin{array}{c}\text { 01 January-15 April } \\
-\end{array}$ \\
\hline Garden area $\left(\mathrm{m}^{2}\right)$ & 66 & 94 & 100 & 104 \\
\hline Irrigation requirement $\left(\mathrm{m}^{3}\right)$ & 37 & 39 & 37 & 45 \\
\hline Irrigation requirement $\left(\mathrm{m}^{3} / \mathrm{m}^{2}\right)$ & 0.557 & 0.402 & 0.372 & 0.431 \\
\hline Crop production $(\mathrm{kg} / \mathrm{yr})$ & 338 & 370 & 369 & 416 \\
\hline Revenue $(€ /$ yr $) *$ & 65 & 105 & 84 & 206 \\
\hline Water efficiency $\left(\mathrm{kg} / \mathrm{m}^{3}\right)$ & 9.2 & 9.8 & 9.9 & 9.3 \\
\hline Water productivity $\left(€ / \mathrm{m}^{3}\right)$ & 1.8 & 2.8 & 2.3 & 4.6 \\
\hline
\end{tabular}

Note: * Exchange rate: 1 Namibian Dollar $(\mathrm{N} \$)=0.0905$ Euro $(€)[35]$.

The low water garden has the lowest irrigation requirement per square meter and the highest water efficiency. The super cash garden has the largest garden area and total irrigation requirements can be higher because it does not contain a fruit tree with high water requirement throughout the whole year, particularly during the dry season starting from May. Crop water requirement of garden variants per square meter with the share covered by irrigation and precipitation is shown in Figure 5.

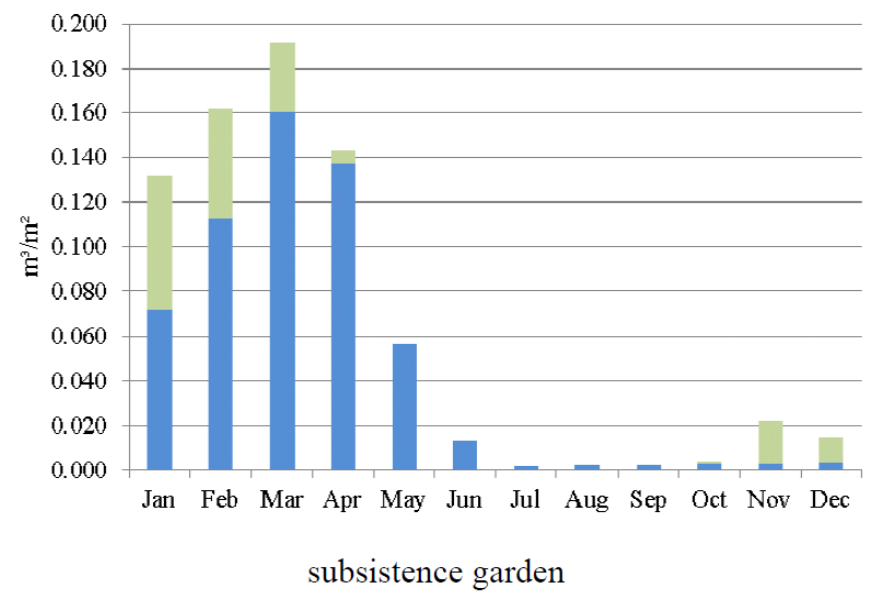

(a)

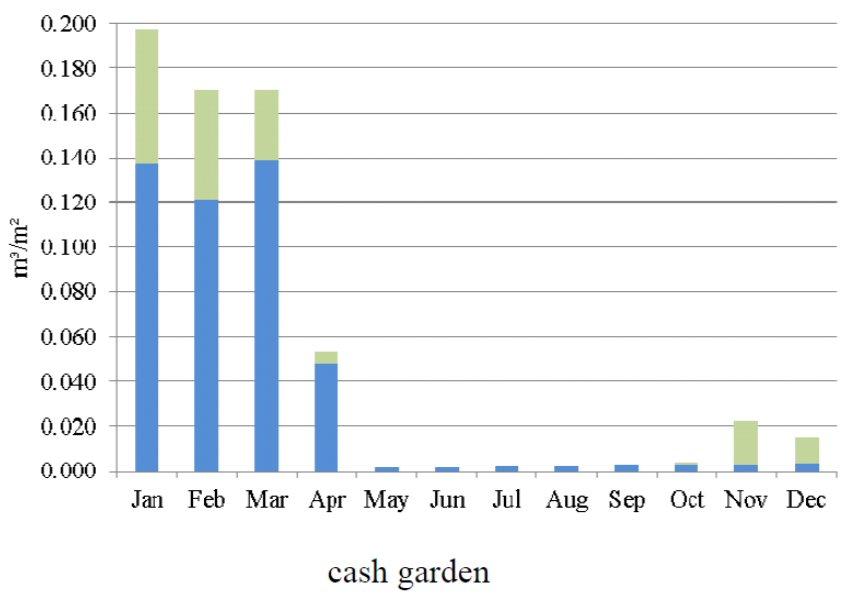

(b)

Figure 5. Cont. 


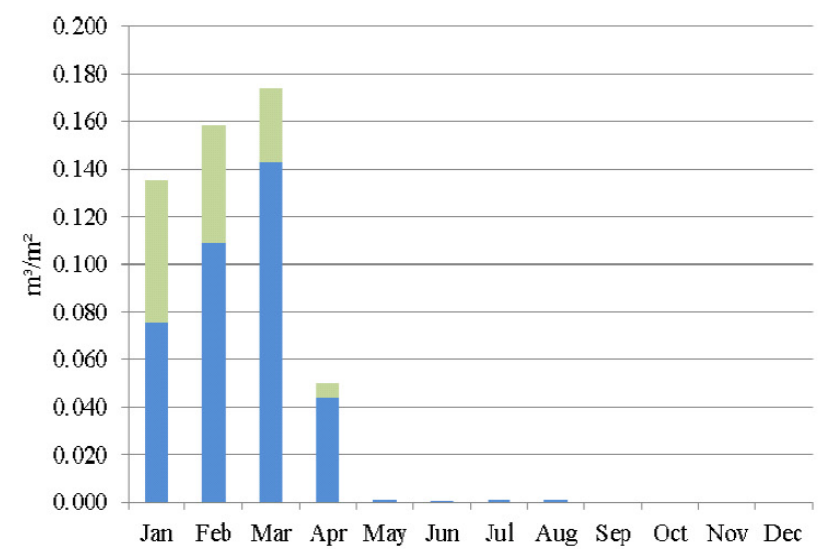

low water garden

(c)

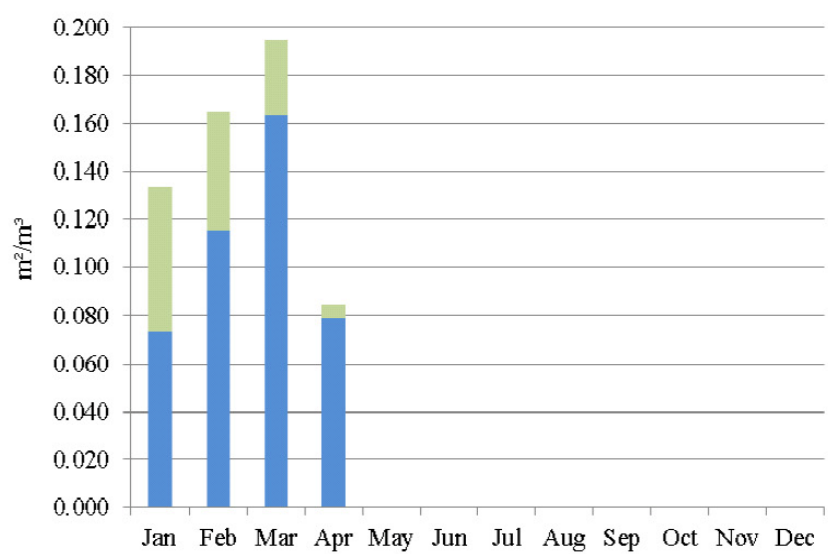

super cash garden

(d)

Figure 5. Crop water requirement $\left(\mathrm{m}^{3} / \mathrm{m}^{2}\right)$ with share covered by irrigation with harvested rainwater (blue) and precipitation (75\% dependable rainfall) (green). Data base: [28,34]. (a) for subsistence garden; (b) for cash garden; (c) for low water garden; and (d) for super cash garden.

The crop water requirement $\left(\mathrm{ET}_{\mathrm{c}}\right)$ and its share covered from precipitation and irrigation requirement were calculated with CROPWAT 8.0. The irrigation requirement calculated is equal to irrigation with harvested rainwater.

\subsection{Analysis of Climate Change Impacts}

Two effects lead to increased irrigation requirements: first, raising temperatures lead to an increase in crop evapotranspiration and therefore crop water requirements; and second, decreasing precipitation leads to a decrease in the rain-fed proportion of crop water requirements (Figure 6). In addition, decreased precipitation decreases the amount of harvested rainwater. When irrigation requirements increase while the amount of harvested rainwater decreases, the risk of water-related harvest loss increases significantly. The extent to which climate change decreases the reliability of the irrigation schemes depends on both the garden variant and the climate change scenario.

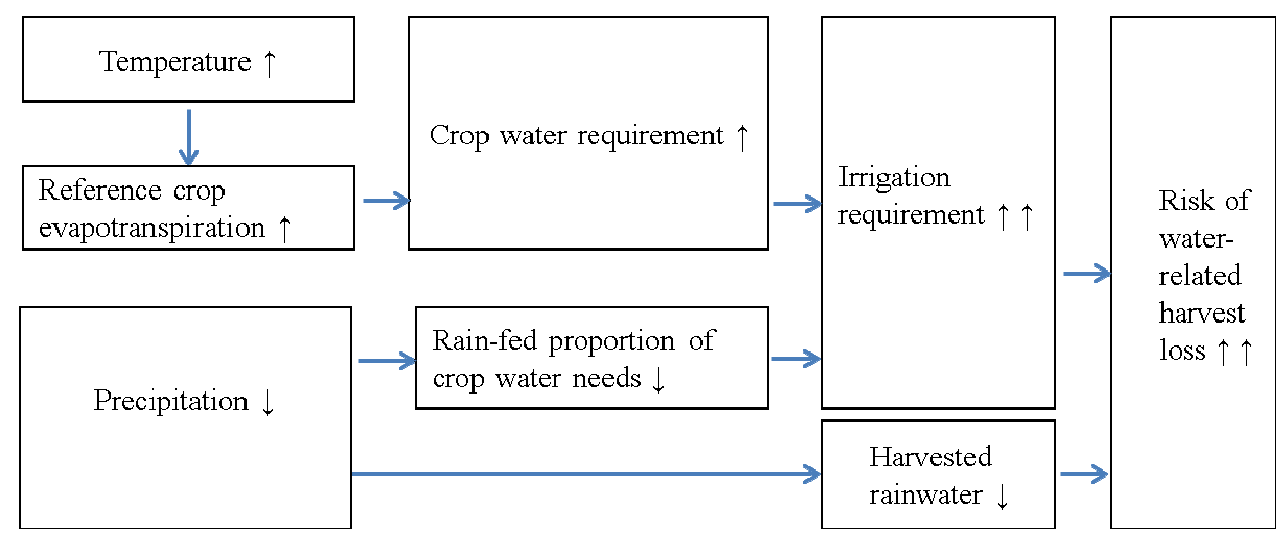

Figure 6. Impacts of worsening future climate conditions with higher temperatures and less precipitation on rainwater harvesting. 
We projected irrigation requirements to increase in all three climate scenarios (Figure 7), averaged over all garden variants from $+3 \%$ in the best to $+12 \%$ in the worst climate case scenario.

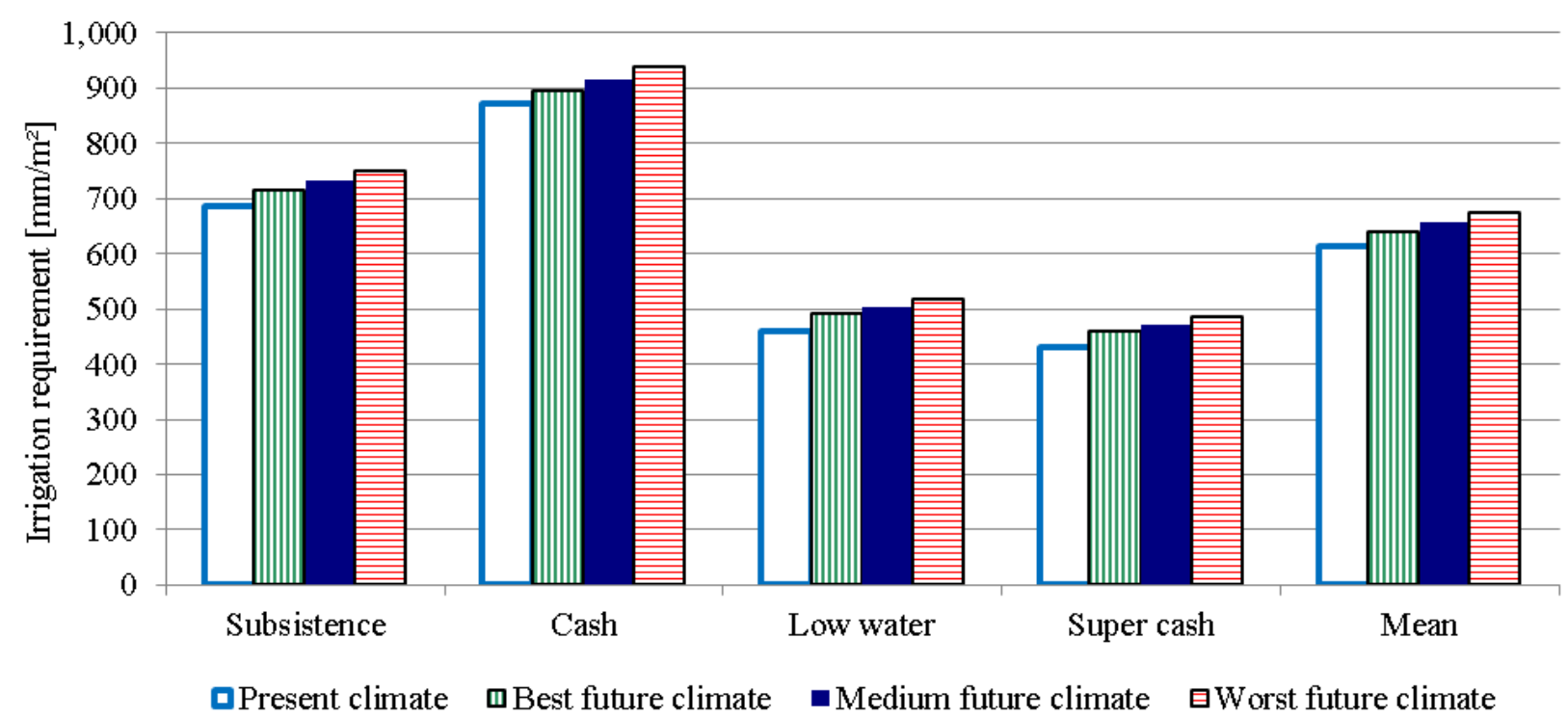

Figure 7. Irrigation requirement for present climate and projected for $2050\left(\mathrm{~mm} / \mathrm{m}^{2}\right)$ (data base: $[10,30,32])$.

With garden sizes optimized for current climate conditions, irrigation requirements can be fully covered with harvested rainwater in fewer years (Figure 6), i.e., the risk of water related harvest loss increases. Under the worst-case climate scenario (Figure 8), irrigation requirements would be met in only $40 \%-47 \%$ of years, as compared to $77 \%$ under current climate conditions, depending on the garden variant. In the medium-case climate scenario, the respective values range between $53 \%$ and $67 \%$. Only under the best-case scenario, irrigation water requirements can be satisfied with a similar frequency as under current climate conditions. Climate change has the lowest negative impact on the risk of water-related harvest loss in the case of the low water garden and the cash garden, for which the reliability of water supply decreases to only $47 \%$ of all years in the worst-case climate scenario. The highest impact is expected for the super cash garden, with most strongly decreased reliability for all climate scenarios, and a decrease to $53 \%$ and $40 \%$ in the medium and worst case, respectively. One reason for this is that the area of the super cash garden is optimized to store just enough water until the end of the growth period of its field crops in May. With deteriorating climate conditions, there is not enough buffer and the tank runs dry more frequently compared to the other gardens that are optimized to store water in the tank throughout the whole year for the tree. 


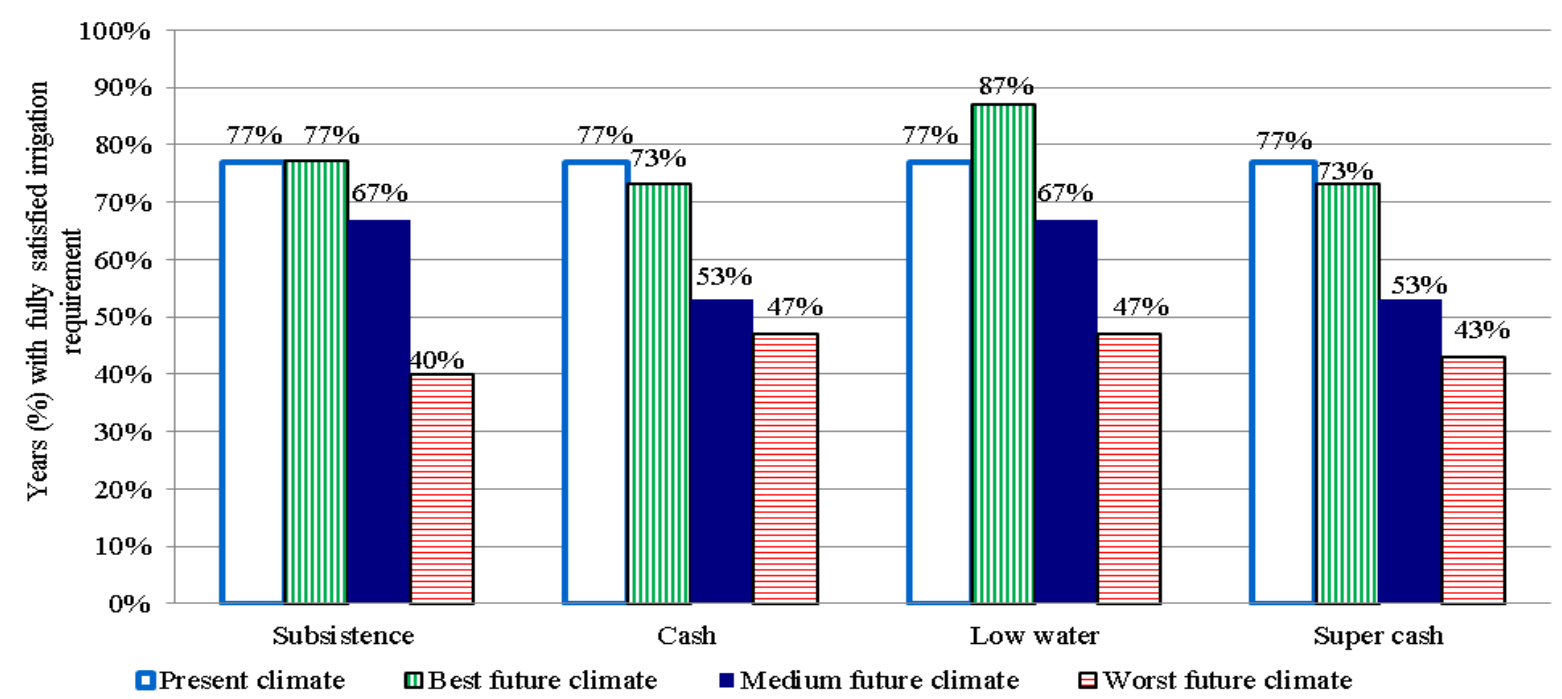

Figure 8. Proportion of years (\%) with fully satisfied irrigation requirements leading to full yield, without adaptation measures. The garden area is optimized for current climate conditions (a satisfaction of irrigation requirements in $77 \%$ of years refers to a probability of 3 out of 4 years, equal to 7 out of 30 years in the monthly time series).

\subsection{Development of Adaptation Strategies to Climate Change}

The possible, viable identified and evaluated measures to adapt the rainwater harvesting facility and the garden to future climate are shown in (Table 4). Nonetheless, the study showed that future climate scenarios play a minor role and have a lower impact on gardening yields compared to the more dominant role of the selected garden variant.

Table 4. Adaptation measures.

\begin{tabular}{|c|c|c|}
\hline Adaptation Measure & Effect & $\begin{array}{c}\text { Complete Compensation of Worst } \\
\text { Future Climate Scenario }\end{array}$ \\
\hline Adaptation of garden area & Fully irrigate a smaller garden area & $\begin{array}{l}\text { Yes. Disadvantage: Yield and } \\
\text { revenue reduction. }\end{array}$ \\
\hline $\begin{array}{l}\text { Switch to garden variant with } \\
\text { higher water efficiency }\end{array}$ & $\begin{array}{l}\text { Rise in water efficiency of e.g., }+8 \% \\
\text { when switching from the subsistence } \\
\text { to the low water garden }\end{array}$ & $\begin{array}{l}\text { Partly. Only possible for gardens with low } \\
\text { water efficiency and by changing the } \\
\text { strategic goal of a farmer. }\end{array}$ \\
\hline $\begin{array}{l}\text { Purchase of irrigation } \\
\text { water from the grid }\end{array}$ & Garden can be continuously irrigated & Yes. \\
\hline $\begin{array}{l}\text { Adaptation of the roof } \\
\text { catchment size }\end{array}$ & More rain can be harvested & $\begin{array}{l}\text { Yes. With an extension of the roof by }+10 \% \\
\text { (current: } 100 \mathrm{~m}^{2} \text { roof, } 28.4 \mathrm{~m}^{3} \text { harvested } \\
\text { rainwater) } 28.7 \mathrm{~m}^{3} \text { can be harvested under } \\
\text { the worst case climate scenario. } \\
\text { Disadvantage: costs and practicability. }\end{array}$ \\
\hline $\begin{array}{l}\text { Observation of water quantity } \\
\text { stored and early reaction in case } \\
\text { water is not sufficient }\end{array}$ & Result was not significant & No. \\
\hline
\end{tabular}




\subsubsection{Adaptation of Garden Area}

Under the various climate scenarios, the garden size would have to be adjusted to ensure that the risk of water-related harvest loss remains at its value under the current climate (Figure 9). With this adaptation of the garden area, the harvested rain is sufficient to irrigate the full garden area, even if smaller, also in the future. Gradually adapting the garden area to the best future climate scenario would mean an enlargement for the subsistence garden variant until 2050 from 66 to $67 \mathrm{~m}^{2}(+2 \%)$ and the low water garden variant $(+1 \%)$ from 100 to $101 \mathrm{~m}^{2}$, an unchanged size for the cash garden and a reduction for the super cash garden from 104 to $96 \mathrm{~m}^{2}(-8 \%)$. The medium scenario requires a reduction $(-10 \%$ to $-16 \%)$ and the worst climate scenario a considerable reduction of the garden area $(-16 \%$ to $-31 \%)$. With a smaller garden area, yields and revenues from gardening will decrease proportionally in the future. Although the super cash garden size requires the greatest reduction in all climate scenarios, its revenue remains the highest of all garden variants, even under the worst-case climate scenario. This measure is viable, but it also has negative consequences on yield and revenues under the medium and worst climate scenario. In practice, it might not always be possible to adapt a garden size to the design or available water, but the garden size is often related to the maximum available garden size due to space constraints and property size.

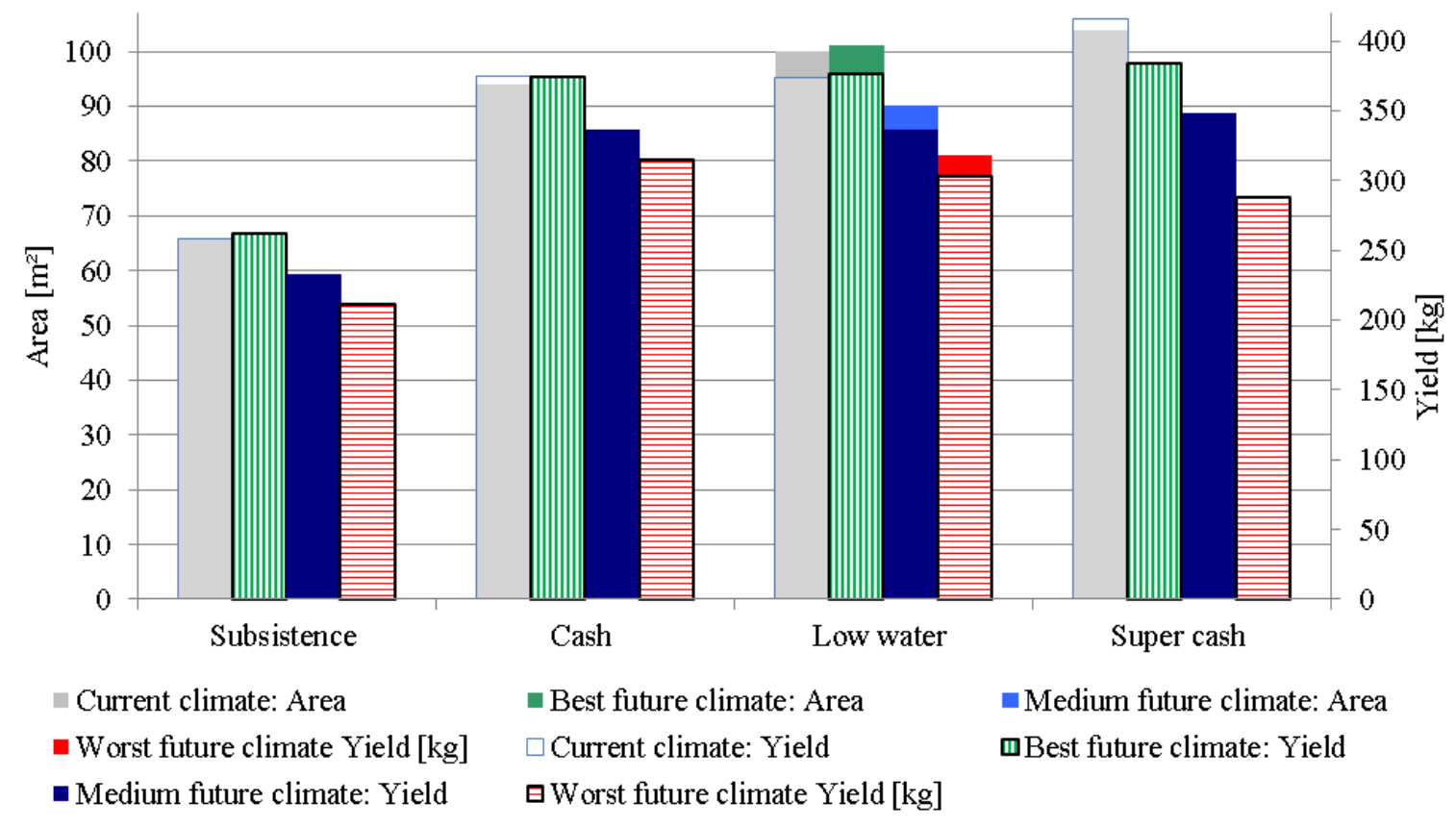

Figure 9. Area $\left(\mathrm{m}^{2}\right)$ and yield $(\mathrm{kg})$ of gardens with adapted area that can be fully irrigated depending on climate scenario (full irrigation in three out of four years).

\subsubsection{Switch to Garden Variant with Higher Water Efficiency}

A switch of the garden variant towards more water efficient crops can compensate deteriorating future climate conditions. A switch from the subsistence garden variant $\left(9.2 \mathrm{~kg} / \mathrm{m}^{3}\right)$ to the low water garden variant $\left(9.9 \mathrm{~kg} / \mathrm{m}^{3}\right)$ entails a rise in water efficiency of $+8 \%$ (Table 3 ). Figure 9 shows that the most water efficient low water garden variant can be irrigated on a larger area even under the worst 
climate scenario $\left(81 \mathrm{~m}^{2}\right.$ and $\left.299 \mathrm{~kg}\right)$ than the subsistence garden variant in the most favorable best future climate scenario $\left(67 \mathrm{~m}^{2}\right.$ and $\left.273 \mathrm{~kg}\right)$. When cultivating a garden with higher water efficiency already under current climate conditions, the water efficiency cannot be raised any further and deteriorating climate conditions cannot be compensated. When changing the garden variant, the strategic goal behind a specific garden variant also changes. Evaluation of all proposed adaptation measures revealed that this is the most effective and practicable measure. However, this has repercussions on the crop type and variety, the daily diet, yield and market revenues. In addition, the choice of crops in a garden mostly depends on personal reasons (e.g., socio-economic factors) of the farmer. Also in practice, gardeners can grow a variety of crops that are not consistent with each scenario. However, each crop has a specific water use efficiency that needs to be considered. In addition, field crops can be changed easily after each growing season, while perennial crops, such as fruit trees cannot be changed as easily.

\subsubsection{Purchase of Tap Water}

We calculated that purchase of additional irrigation water from public water supply is mostly profitable, as current drinking water prices $\left(0.81 € / \mathrm{m}^{3}\right)$ are mostly below the resulting economic loss that would occur due to lack of harvested water. However, the viability of this measure is questioned considering that climate change will aggravate the water scarcity in semi-arid regions. On a large scale, the use of freshwater for agriculture is not an environmentally sustainable option, however in the case of small-scale gardening it might still be viable if practiced temporary and to a low extent. The profitability of purchasing tap water might also change in the future with changing water and crop prices. In addition, purchasing tap water might also increase the inequity in a community if the supply of drinking water is limited and the affordability unequal.

\subsubsection{Enlargement of Roof Size}

A further measure is the adaptation of the roof catchment size. Presently, a $100-\mathrm{m}^{2}$ roof can harvest $28.4 \mathrm{~m}^{3}$ of rainfall per year. Under the worst climate conditions, only $26.1 \mathrm{~m}^{3}$ will be harvested. When extending the roof to $110 \mathrm{~m}^{2}(+10 \%)$, using Equation (2), results show that $28.7 \mathrm{~m}^{3}(+1 \%)$ can be harvested in the worst climate scenario, $30.4 \mathrm{~m}^{3}(+7 \%)$ in the medium climate scenario and $32.5 \mathrm{~m}^{3}$ $(+14 \%)$ in the best climate scenario in 2050 compared to the current climate conditions. Therefore an enlargement of the roof size by $+10 \%$ is enough to compensate the effects of the worst climate scenario. This measure is therefore useful, though it is tied to additional expenses for corrugated sheet, gutters and downpipes and might not always be practicable.

For most households, it might be easier to increase the storage capacity instead of increasing the roof area. The problem is, however that leaving the roof the same size and enlarging the tank will not harvest more water and the tank would be oversized.

\subsubsection{Observation of Water Level and then Reduction of Garden Area}

A fifth measure could be to regularly measure the water in the tank, considering the volume as a sign of early warning for future lack of tank water. If water volume were found to be unusually low, 
the irrigated area could be reduced. We defined the sign as the ratio of water volume stored at the end of a month relative to the water volume to be withdrawn in the next month. Then we tested this sign on our 30-year time series. However, such a sign proved not to be significant as the sign indicated a subsequent tank failure two months in advance in only $10 \%$ of cases and one month in advance in $11 \%$ of cases. In the remainder of cases, the sign indicated a warning even though no tank failure occurred.

\subsection{Applicability and Limitations of Results and Methodology}

The methodology applied in this study has potential for a wide field of applications. More generalized results, independent of specific tank or roof size, could be achieved by integrating dimensionless approaches into a model, such as the one used, for instance, by Fewkes and Butler [36] or Campisano and Modica [37]. The methodology presented in this study can also be applied for instance, for rainwater stored in all kinds of reservoirs with different dimensions, transferred to other regions with different climatic and natural conditions, or applied for other water use purposes, such as for drinking water, for livestock or using harvested rainwater in combination with other sources of water, such as treated wastewater. Then the model needs to be adapted concerning the amounts of possible water supply or garden water requirements. The adaptation measures proposed in this study can be transferred to other semi-arid regions with short rainy seasons.

This study did not include evaporation from the ferrocement tank, as the tank is covered and evaporation is estimated to be minimal. Also leakage from the tank was not considered due to a lack of reliable data. Leakage might occur, however, especially after a few years if tanks are not maintained well. Future studies would need to include a percentage that is deducted from the water stored due to leaking.

Limitations of this study include the assumptions on the regionalized climate projections. To estimate climate change for central-northern Namibia until 2050, this study estimated future precipitation, temperature and reference crop evapotranspiration by adjusting climate projections for 2080-2099 that are averaged for the whole South African subcontinent. Changes in relative humidity, wind speed and length of daily sunshine hours are highly uncertain and were not taken into account for the estimation of future reference crop evapotranspiration. Increase in temperature may affect the length of the growing season, or temperatures may become too high for the cultivation of certain crops. In addition, the change in daily and inter-annual rainfall variability was not considered. However, the expected increase of rainfall variability and heavy precipitation events [3] is likely to impact rainwater harvesting in a negative way. High quantities of precipitation falling in fewer days do not have an impact as long as the tank is not full yet. However, if more rainwater comes at once, the tank is more likely to spill over. Extreme rainfall events also mean that more rain falls on the garden area at once, increasing runoff while the rain cannot infiltrate and be taken up by crops. Then more water is needed for irrigation. Increased inter-annual rainfall variability would decrease the $75 \%$ dependable monthly rainfall even if mean values would remain the same. Floods and extreme rainfall events also raise the risk for crop damage and failure. Nonetheless, our climate projections for 2050 cover the full range of uncertainty and are a helpful guide to establish impacts and identify the extent of necessary adaptation measures. In order to refine the results of this study, future studies need to integrate climate data projections for 2050, including precipitation, temperature, relative humidity, wind speed and 
sunshine hours down-scaled for north-central Namibia, made available for instance by the Earth System Grid Federation (ESGF).

A further limitation of the methodology applied in this study is the use of monthly time steps, while literature indicates that using reduced time steps may improve significantly the accuracy of the results [36]. Nonetheless, Fewkes and Butler [37] suggest that using a model with monthly time steps is justified with storage fractions above 0.125 . The storage fraction is given by $S /(A R)$, where $S=$ storage capacity $\left[\mathrm{m}^{3}\right], A=$ roof area $\left[\mathrm{m}^{2}\right]$ and $R=$ annual rainfall $[\mathrm{m}]$. In the case of the study the storage fraction is $30 \mathrm{~m}^{3} /\left(100 \mathrm{~m}^{2} \times 0.47 \mathrm{~m}\right)=0.64$. The relatively large storage fraction indicates that the tank and the roof size are big enough so that relatively large amounts of water can be stored in relation to low annual rainfall. Therefore the use of monthly time steps in this study is justified. Further studies, could refine the results of this study by using a tank model and computing irrigation requirements with daily time steps.

This study demonstrated an approach to design garden variants that can be safely supplied with harvested rainwater, taking into account climate change and adaptation measures. In addition, the study also presented an approach to quantify the effects of climate change on rainwater harvesting based gardening. Other studies have also reported rainwater harvesting storage tanks to have positive impacts for the adaptation to climate change, in other contexts beyond gardening and rural Africa (see for instance $[37,38]$ )

\section{Conclusions}

(1) Two important factors influencing the yield that can be achieved with rainwater harvesting based gardening are the household's decision regarding a certain garden variant and future climate conditions.

(2) Except for the best-case climate scenario, climate change is projected to lead to considerable negative impacts on rainwater harvesting and gardening. The risk of water-related harvest losses would increase if garden sizes and, thus, revenues are not decreased.

(3) This study demonstrated a methodology to quantify the effects of climate change on rainwater harvesting based gardening. The actual values resulted in the study may not be accurate due to the assumptions made for climate projections in this study and may be refined with further studies.

(4) Viable measures to adapt rainwater harvesting and gardening to the prevailing climate situation in the future include an extension of the roof size, the purchase of additional tap water and a switch from low water efficient crops to high water efficient crops. When taking these measures, the negative impacts of climate change can be partly or completely compensated, however each tied to specific repercussions.

\section{Acknowledgments}

This research was carried out within the research project "CuveWaters-Integrated Water Research Management in Namibia” by the Institute for Social Ecological Research (ISOE) and the Technische Universität Darmstadt and funded by the German Federal Ministry for Education and Research (BMBF). 


\section{Author Contributions}

The text was prepared by Laura Woltersdorf based on results of her Master thesis. Stefan Liehr and Petra Döll supervised the Master thesis and the preparation of the article, supported with discussions, conceptualization, structuring and added passages to the article.

\section{Conflicts of Interest}

The authors declare no conflict of interest.

\section{References}

1. Climate Change 2007: Synthesis Report-Summary for Policymakers. Intergovernmental Panel on Climate Change Fourth Assessment Report, Contributions of Working Groups I, II, and III. IPCC: Geneva, Switzerland, 2007.

2. International Water Management Institute (IWMI). Water for Food, Water for Life: $A$ Comprehensive Assessment of Water Management in Agriculture; Earthscan: London, UK; Colombo, Sri Lanka, 2007; p. 40.

3. Bates, B.C.; Kundzewicz, Z.W.; Wu, S.; Palutikof, J.P. Climate Change and Water; Intergovernmental Panel on Climate Change (IPCC Secretariat): Geneva, Switzerland, 2008, p. 210.

4. Barron, J. Rainwater Harvesting: A Lifeline for Human Well-Being; United Nations Environment Programme (UNEP), Stockholm Environment Institute (SEI): Stockholm, Sweden, 2009; p. 80.

5. Ishaku, H.T.; Rafee Majid, M.; Johar, F. Rainwater harvesting: An alternative to safe water supply in Nigerian rural communities. J. Water Resour. Manag. 2012, 26, 295-305.

6. Pachpute, J.S.; Tumbo, S.D.; Sally, H.; Mul, M.L. Sustainability of rainwater harvesting systems in rural catchment of sub-Saharan Africa. J. Water Resour. Manag. 2009, 23, 2815-2839.

7. Sturm, M.; Zimmermann, M.; Schütz, K.; Urban, W.; Hartung, H. Rainwater harvesting as an alternative water resource in rural sites in central northern Namibia. Phys. Chem. Earth A/B/C 2009, 34, 776-785.

8. Water is Life-Omeya ogo Omwenyo; CuveWaters Mid-Term Report; Institute for Social-Ecological Research (ISOE) GmbH: Frankfurt, Germany, 2013.

9. Critchley, W.; Siegert, K.; Chapman, C. Water Harvesting: A Manual for the Design and Construction of Water Harvesting Schemes for Plant Production; Food and Agricultural Organization (FAO): Rome, Italy, 1991. Available online: http://www.fao.org/ag/magazine/ 0704sp4.htm (accessed on 6 February 2012).

10. Christensen, J.H.; Hewitson, B.; Busuioc, A.; Chen, A.; Gao, X.; Held, I.; Jones, R.; Kolli, R.K.; Kwon, W.T.; Laprise, R.; et al. Regional climate projections. In Contribution of Working Group I to the Fourth Assessment Report of the Intergovernmental Panel on Climate Change. Supplementary Material. Regional Climate Projections; Solomon, S., Qin, D., Manning, M., Chen, Z., Marquis, M., Averyt, K.B., Tignor, M., Miller, H.L., Eds.; Cambridge University Press: Cambridge, UK; New York, NY, USA, 2007. 
11. Biazin, B.; Sterk, G.; Temesgen, M.; Abdulkedir, A.; Stroosnijder, L. Rainwater harvesting and management in rainfed agricultural systems in sub-Saharan Africa-A review. Phys. Chem. Earth 2012, 47-48, 139-151.

12. Kahinda, M.; Taigbenu, A.E. Rainwater harvesting in South Africa: Challenges and opportunities. Phys. Chem. Earth A/B/C 2011, 36, 968-976.

13. Boelee, E.; Mekonnen, Y.; Poda, J.; McCartney, M.; Cecchi, P.; Kibret, S.; Hagos, F.; Laamrani, H. Options for water storage and rainwater harvesting to improve health and resilience against climate change in Africa. Reg. Environ. Chang. 2013, 13, 509-519.

14. Kahinda, M.; Taigbenu, A.E.; Boroto, R.J. Domestic rainwater harvesting as an adaptation measure to climate change in South Africa. Phys. Chem. Earth A/B/C 2010, 35, 742-751.

15. Lupia, F.; Pulighe, P. Water use and urban agriculture: Estimation and water saving scenarios for residential kitchen gardens. In Proceedings of the IRLA 2014, The Effects of Irrigation and Drainage on Rural and Urban Landscapes, Patras, Greece, 26-28 November 2014.

16. Hajani, E.; Rahman, A. Reliability and cost analysis of a rainwater harvesting system in peri-urban regions of Greater Sydney, Australia. Water 2014, 6, 945-960.

17. Gould, J.; Nissen-Petersen, E. Rainwater Catchment SYSTEMS for Domestic Supply; Intermediate Technology Publications: Warwickshire, UK, 2006.

18. Kluge, T.; Liehr, S.; Lux, A.; Moser, P.; Niemann, S.; Umaluf, N.; Urban, W. IWRM concept for the Cuvelai Basin in northern Namibia. Phys. Chem. Earth A/B/C 2008, 33, 48-55.

19. Heyns, P. The Namibian perspective on regional collaboration in the joint development of international water resources. Int. J. Water Resour. Dev. 1995, 11, 467-492.

20. Liehr, S. Driving forces and future development paths of central northern Namibia. In Exploring Sustainability Science: A Southern African Perspective; Burnes, M., Weaver, A., Eds.; African Sun Media (ASM): Stellenbosch, South Africa, 2008; pp. 431-467.

21. Reid, H.; Sahlén, L.; MacGregor, J.; Stage, J. The Economic Impact of Climate Change in Namibia Impact of Climate Change in Namibia: How Climate Change Will Affect the Contribution of Namibia's Natural Resources to Its Economy; Environmental Economics Programme: London, UK, 2007.

22. Government of Namibia. Namibia Initial National Communication to the United Nations Framework Convention on Climate Change; Government of Namibia: Windhoek, Namibia, 2002

23. Jokisch, A.; Kariuki, I.; Woltersdorf, L.; Zimmermann, M.; Brenda, M.; Polak, M. Rainwater Harvesting for Micro-Scale Gardening within the Frame of Project CuveWaters Planning, Construction and Operation of Pilot Plants 2009-2011; Internal Working Paper: Technische Universität Darmstadt, Darmstadt, Germany, 2011.

24. Zimmermann, M.; Jokisch, A.; Deffner, L.; Brenda, M.; Urban, W. Stakeholder participation and capacity development during the implementation of rainwater harvesting pilot plants in Central Northern Namibia. Water Sci. Technol. 2012, 12, 540-548.

25. Woltersdorf, L.; Jokisch, A.; Kluge, T. Benefits of rainwater harvesting for gardening and implications for future policy in Namibia. Water Policy 2014, 16, 124-143.

26. Mendelsohn, J.; El Obeid, S.; Roberts, C. A Profile of North-Central Namibia; Environmental Profiles Project; Gamsberg Macmillan Publishers: Windhoek, Namibia, 2000. 
27. Lütkemeier, R. Map of Namibia with North-Central Namibia; Map Made with Natural Earth; Institute for Social-Ecological Research ISOE: Frankfurt, Germany, 2015.

28. Savva, A.; Frenken, K. Crop Water Requirements and Irrigation Scheduling; Irrigation Manual Module 11; Food and Agricultural Organization (FAO): Rome, Italy, 2002.

29. Brouwer, C.; Prins, K.; Heibloem, K. Irrigation Water Management: Irrigation Scheduling; Training manual no. 4; Food and Agricultural Organization (FAO): Rome, Italy, 1989.

30. Provision of Weather Data Regarding Temperature, Precipitation, Wind Speed, and Humidity; Namibian Weather Bureau: Windhoek, Namibia, 2011.

31. The World Bank. Climate portal of the World Bank. Climate Data Namibia. Available online: http://sdwebx.worldbank.org/climateportal/ (accessed on 2 October 2010).

32. Nakicenovic, N.; Swart, R. IPCC Special Report Emission Scenarios: Summary for Policymakers. A Special Report of IPCC Working Group III; Cambridge University Press: Cambridge, UK; New York, NY, USA, 2000; p. 27.

33. Irrigation Development in Namibia: Green Scheme and Horticulture Initiative for Namibia-Cost /Benefit Analysis; Price Waterhouse Coopers: Windhoek, Namibia, 2005.

34. Nantanga, K.; Mazambani, C.; Kruger, B. Small Scale Irrigation and Aquaculture in Central Northern Namibia; Unpublished Technical Report; Desert Research Foundation of Namibia: Windhoek, Namibia, 2007.

35. OANDA Corporation. Online Currency Converter. 2011. Available online: http://www.oanda.com/ (accessed on 31 October 2011).

36. Fewkes, A.; Butler, D. Simulating the performance of rainwater collection systems using behavioural models. Build. Serv. Eng. Res. Technol. 2000, 21, 99-106.

37. Campisano, A.; Nie, L.; Li, P. Retention performance of domestic rain water harvesting tank under climate change conditions. Appl. Mech. Mater. 2013, 438-439, 451-458.

38. Lash, D.; Ward, S.; Kershaw, T.; Butler, D.; Eames, M. Robust rainwater harvesting: Probabilistic tank sizing for climate change adaptation. J. Water Climate Chang. 2014, 5, 526-539.

(C) 2015 by the authors; licensee MDPI, Basel, Switzerland. This article is an open access article distributed under the terms and conditions of the Creative Commons Attribution license (http://creativecommons.org/licenses/by/4.0/). 